\title{
Effects of Smoking Behaviors on Maternal Conditions and Conditions Arising during the Perinatal Period among Women of Reproductive Age
}

\author{
Hyun-Jung Park, Eun-Jung Kim \\ Department of Nursing, Pyeongtaek University, Pyeongtaek, Korea
}

Purpose: This study analyzes the effects of smoking behaviors of women of reproductive ages in terms of maternal conditions and conditions arising during the perinatal period in Korea. Methods: We used the National Health Insurance Corporation's medical panel data. Subjects included 382 individuals suffering from maternal conditions and conditions arising during the perinatal period from 2013 to 2014. A t-test was used to analyze the individual differences between maternal conditions and conditions arising during the perinatal period-A hierarchical regression analysis was performed in two steps to measure the effects of smoking behaviors on diseases. Results: The amount and duration of smoking are significant factors causing maternal conditions and conditions arising during the perinatal period. In the regression analysis, the explanatory power of model was significantly increased by adding smoking behavior to the maternal conditions and conditions arising during the perinatal period. Smoking behavior during pregnancy displayed a significant influence on diseases. Conclusion: Results of this study showed that the effects of smoking behavior on maternal conditions and conditions arising during the perinatal period were significant. Therefore it is necessary to develop a smoking cessation education program for pregnant women in Korea.

Key words: Smoking, Behavior, Pregnant women, Smoking prevention

\section{Corresponding author Eun-Jung Kim \\ https://orcid.org/0000-0003-2352-5267 \\ Department of Nursing, Pyeongtaek University, 3825 Seodong-daero, Pyeongtaek 17869, Korea \\ TEL +82-31-659-8301 FAX +82-31-659-8011 \\ E-MAIL ejkim7888@gmail.com}

*This study was supported by the research fund of Pyeongtaek University in 2017.

Received Jun 15, 2018 Revised Jul 1, 2018 Accepted Jul 5, 2018
(3) This is an Open Access article distributed under the terms of the Creative Commons Attribution NonCommercial License (http://creativecommons.org/licenses/by-nc/4.0/) which permits unrestricted noncommercial use, distribution, and reproduction in any medium, provided the original work is properly cited.

\section{INTRODUCTION}

Since 2000, smoking rates across most Organization for Economic Cooperation and Development (OECD) countries have declined. On average, smoking rates in the OECD have decreased since 2000 , from $26 \%$ to $20 \%$ in 2013 [1].

The smoking rate of adult women in Korea has remained relatively constant for the past 16 years from $6.5 \%$ in 1998 to $5.7 \%$ in 2014 [2]. Interestingly, however, through urine nicotine measurements the smoking rate of domestic women was $13.9 \%$, which was higher than the reported self-reported smoking rate of 5.9\%[2]. This is because the smoking rate of Korean women has been under reported since women tend to hide their smoking habits for cultural reasons [2]. According to the trend of the smoking rate in Korea in 2016, the smoking rate was the highest in high school students, and the rate constantly increased among women in the 20s to 40s age-range, with one in ten women of reproductive age (20s 40 s) being a smoker [3].

It is true that smoking causes health problems for both men and women, though women have different risks of tobacco-related health problems than men. Not only is tobacco exposure during pregnancy dangerous to the immediate health 
of the baby and its mother, it could potentially contribute to serious health problems during the child's entire life [4]. Since women are responsible for pregnancy, childbirth and child care, women's smoking could affect their fetus and family members, not to mention their own bodies, and this tends to create social problems [5]. Problems associated with women's smoking include a decrease in the pregnancy rate, and increases in cervical cancer, osteoporosis, menstrual irregularities and premature menopause; smoking among pregnant women is associated with miscarriages, premature births, low birth weights, fetal anomalies, stillbirths, placenta previa, placental abruptions, delayed growth of infants and respiratory distress [6]. Women's smoking is also with a greater likelihood of ectopic pregnancies. It has been estimated that women who smoke more than 20 cigarettes a day are 4 times more likely to have an ectopic pregnancy compared to non-smokers [7]. As another concern, babies born to smoking women are at greater risk of exposure to respiratory or development of mental illness. Up to $10 \%$ of neonatal deaths and $20 \sim 30 \%$ of low birth weights are reported to be caused by smoking during pregnancy [8].

Despite such health risks few institutions in Korea provide smoking cessation programs for women, and women-specific factors are insufficiently reflected in current anti-smoking policies. In addition, most studies exploring the relevance of smoking to adult illnesses merely focus on the mortality and disease risks, regardless of gender, with few studies conducted on the effects of smoking on conditions arising in both the mother and fetus during the perinatal period.

We expect our study set a benchmark for the development prevention policies to address maternal conditions, conditions arising during the perinatal period, the establishment of as well as smoking cessation education programs for women of reproductive age.

\section{Objectives}

The purpose of this study is to analyze the effects of smoking behavior of women of reproductive age in Korea in terms of maternal conditions and conditions arising during the perinatal period.

- To benchmark the current status of maternal conditions and conditions arising during the perinatal period.

- To determine the difference of maternal conditions and conditions arising during the perinatal period status according to the general characteristics and smoking behaviors.

- To determine the effect of smoking behavior on maternal conditions and conditions arising during the perinatal period.

\section{METHODS}

\section{Research Design}

The data used in this study was obtained from medical panel data of the National Health Insurance Corporation from 2009 to 2014. The data survey was carried out a the consortium of the Korea Institute for Health and Social Affairs and the National Health Insurance Corporation, and is a government-designated statistical survey approved by the National Statistics Office (NSO) (Approval No. 33110). The survey was initially conducted twice a year to ensure data accuracy and efficient management of panel households, but since 2012, the survey frequency was reduced to once per year.

The survey of the panel data was conducted from April 2008 for 24,616 household members from 7,866 households in Korea using the second step probability proportional stratified population extraction method. Using the Korean medical panel data, it is possible to identify individuals' diagnosed diseases and their health examination data, and the data is also linked to a questionnaire on their usual health behavior. The subjects included in this study were 382 individuals suffering from maternal conditions and conditions that have arisen during the perinatal period from 2013 to 2014, based on smoking behavior information from 14,213 household members who remained in the same households for six years from 2009 to 2012. This data was obtained from the Korea Institute for Health and Social Affairs, Korea Bioethics Committee (IRB No. 2017-04).

\section{Study Population}

This study investigates the effects of smoking on maternal conditions and conditions arising during the perinatal period that may occur at birth for women aged 15 to 44 . Thus, the questionnaire for the study was focused on the effects of smoking on maternal conditions (e.g. maternal hemorrhage, sepsis, gestational hypertension, dystocia, abortion, etc.) and conditions arising during the perinatal period (e.g. low birth weight, newborn asphyxia and birth injury), using diagnosed codes based on the World Health Organization (WHO) International Code for the Classification of Diseases (ICD-10) for measuring the 'Global Burden of Disease'.

Using this data, we selected our subjects from women ranging from 15 to 44 years of age who had visited medical institutions for the above-mentioned diseases. It could be counted with duplication. Because they could visit hospitals with two more diseases. We used the number of diagnosed diseases as a dependent variable. We then measured the subjects' smoking behavior to discover the independent influence of 
smoking on maternal conditions and conditions arising during the perinatal period (Figure 1).

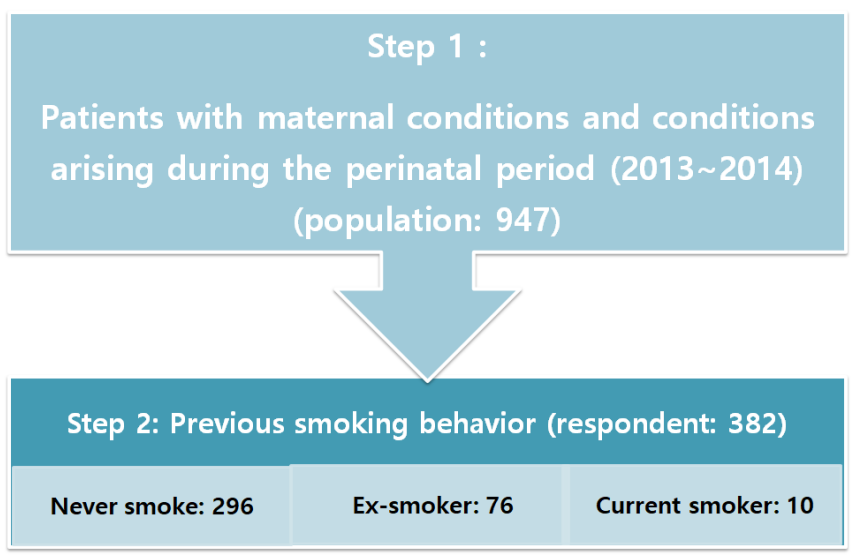

Figure 1. Target population.

\section{Data Collection and Analysis}

In this study, we used the health behaviors questionnaire for our subjects in order to identify their smoking habits. In the 'Do you smoke now?' question, subjects were classified as either non-smokers or smokers. Smokers were then sub-classified as either smokers smoking half pack per day or those smoking more than half pack per day. To adjust for possible confounding variables, characteristics of age group and Body Mass Index (BMI) were calculated as constants and percentages; blood pressure and smoking-related behaviors were calculated as mean and standard deviation. A t-test was used to analyze the individual differences between the number of maternal conditions and conditions arising during the perinatal period. For correlations of major variables, we used the spearman correlation coefficient. For categorization, we coded their smoking status as ' $0=$ never smoked', ' $1=$ ex-smokers', and ' $2=$ current smokers'. Finally, a hierarchical regression analysis was performed in two steps to measure the effects of smoking behavior on diseases number; in the first model, we measured the effects of personal characteristics on disease pattern and in the second model, we added certain variables related to smoking behavior. Data were analyzed using SPSS/ WIN 18.

\section{RESULTS}

Among our 382 subjects, $30.6 \%$ suffered from 3 maternal conditions and $2.6 \%$ from 5 diseases. In terms of perinatal conditions, $16.8 \%$ had 1 disease and $9.7 \%$ had 2 diseases. The 15 to 34 age group accounted for $47.4 \%$ of the total group, with the
35 to 44 age group accounting for the remaining $52.6 \%$ of the total. The mean BMI of subjects was $21.2 \mathrm{~kg} / \mathrm{m}^{2}$ and the mean blood pressure was 120/75 mmHg. Most subjects had never-smoked (77.5\%). Among the smokers, most of them smoked for less than 5 years (69.8\%), smoked less than a half-pack per day $(68.6 \%)$, and 7 packs per year $(81.6 \%)$ (Table 1$)$.

We found differences between the groups according to the number of diseases arising from individual characteristics. In particular, women over 35 years of age were often affected by more maternal conditions and conditions arising during the perinatal period than the younger group. The smokers (both ex smokers and current smokers) got more diseases than never smokers. The duration of smoking had group differences in number of diseases. The smoking pack year was significantly correlated with the number of diseases (Table 2). The number of diseases was positively correlated to the major variables, except for the quantity of smoking (Table 3 ).

Table 4 presents the results of the regression analysis in which we used the number of maternal conditions and conditions arising during the perinatal period as dependent variables and added age, BMI, systolic and diastolic blood pressure, and smoking behavior in a stepwise manner. The addition of smoking behavior to maternal conditions and conditions arising during the perinatal period significantly increased the explanatory power of the model ( $\mathrm{F}=7.01, p=.002)$. Smoking status and the duration of smoking were found to be significantly influenced by maternal conditions and conditions arising during the perinatal period. In the case of age, the effects of smoking displayed changes as the smoking behavior was added (Model 1: $\mathrm{B}=0.08, p<.001$, Model 2: $\mathrm{B}=-1.03, p<$ .001 ); the smoking behavior of younger women had more influence on their maternal conditions and conditions arising during the perinatal period. In addition, the systolic blood pressure had a significant effect on diseases due to smoking behavior ( $\mathrm{B}=1.17, p=.008)$. According to Model 1, the adjusted $\mathrm{R}$ square was .278 and F was 1.62 at a $p$-value of .054 . And in Model 2, the R square was increased to .659 and $F$ was 7.01 at a $p$-value of .002.

\section{DISCUSSION}

This study analyzed the effects of smoking behavior of women of reproductive age in terms of maternal conditions and conditions arising during the perinatal period using the National Health Insurance Corporation medical panel data. Our goal was to use these results as the foundation for establishing pregnancy and childbirth-related disease prevention policy and as a basic reference for developing smoking cessation education programs for women.

The number of diseases among older women was signifi- 
Table 1. State of Patients with Maternal Conditions and Conditions Arising during the Perinatal Period in 2013 2014

\begin{tabular}{|c|c|c|c|c|}
\hline \multirow{2}{*}{\multicolumn{2}{|c|}{$\begin{array}{l}\text { Variables } \\
\text { Maternal conditions* }\end{array}$}} & \multicolumn{2}{|l|}{ Categories } & \multirow{2}{*}{$\begin{array}{c}\mathrm{n}(\%) \text { or } \mathrm{M} \pm \mathrm{SD} \\
165(43.2)\end{array}$} \\
\hline & & Maternal hemorrhage & $\mathrm{O} 20, \mathrm{O} 44, \mathrm{O} 45, \mathrm{O} 46, \mathrm{O} 67, \mathrm{O} 72$ & \\
\hline & & Maternal sepsis & O85, O753 & $157(41.1)$ \\
\hline & & $\begin{array}{l}\text { Hypertensive disorders of } \\
\text { pregnancy }\end{array}$ & O10, O11, O12, O13, O14, O15, O16 & $217(56.8)$ \\
\hline & & Obstructed labor & O64, O65, O66 & $72(18.8)$ \\
\hline & & Abortion & $\mathrm{O} 00, \mathrm{O} 01, \mathrm{O} 02, \mathrm{O} 03, \mathrm{O} 04, \mathrm{O} 05, \mathrm{O} 06, \mathrm{O} 07, \mathrm{O} 08$ & $39(10.2)$ \\
\hline \multirow{2}{*}{\multicolumn{2}{|c|}{$\begin{array}{l}\text { Conditions arising during the } \\
\text { perinatal period* }^{*}\end{array}$}} & Low birth weight & $\begin{array}{l}\text { P07, P22, P25, P26, P27, P28, P612, P77, P52, } \\
\text { H351 }\end{array}$ & $164(42.9)$ \\
\hline & & $\begin{array}{l}\text { Birth asphyxia and birth } \\
\text { trauma }\end{array}$ & P11, P21, P91 & $134(35.1)$ \\
\hline \multirow{7}{*}{\multicolumn{2}{|c|}{ Number of diseases }} & Maternal conditions & 1 & $65(17.0)$ \\
\hline & & & 2 & $57(14.9)$ \\
\hline & & & 3 & $117(30.6)$ \\
\hline & & & 4 & $32(8.4)$ \\
\hline & & & 5 & $10(2.6)$ \\
\hline & & Conditions arising during & 1 & $64(16.8)$ \\
\hline & & the perinatal period & 2 & $37(9.7)$ \\
\hline \multicolumn{2}{|c|}{ Age group (year) } & $\begin{array}{l}\text { Age in years } \\
15 \sim 34 \\
35 \sim 44\end{array}$ & & $\begin{array}{l}46.97 \pm 6.05 \\
181(47.4) \\
201(52.6)\end{array}$ \\
\hline \multicolumn{2}{|c|}{$\operatorname{BMI}\left(\mathrm{kg} / \mathrm{m}^{2}\right)$} & & & $21.2 \pm 0.03$ \\
\hline \multicolumn{2}{|c|}{ Blood pressure (mmHg) } & $\begin{array}{l}\text { Systolic } \\
\text { Diastolic }\end{array}$ & & $\begin{array}{r}120(8.42) \\
75(3.00)\end{array}$ \\
\hline \multirow[t]{4}{*}{$\begin{array}{l}\text { Smoking } \\
\text { behavior }\end{array}$} & $\begin{array}{l}\text { Smoking status } \\
(\mathrm{n}=382)\end{array}$ & $\begin{array}{l}\text { Never smoke } \\
\text { Ex-smoker } \\
\text { Current smokers }\end{array}$ & & $\begin{array}{c}296(77.5) \\
76(19.9) \\
10(2.6)\end{array}$ \\
\hline & $\begin{array}{l}\text { Duration of smoking } \\
(\mathrm{n}=86)\end{array}$ & $\begin{array}{l}\text { Below } 5 \text { years } \\
\text { Over } 5 \text { years }\end{array}$ & & $\begin{array}{l}60(69.8) \\
26(30.2)\end{array}$ \\
\hline & $\begin{array}{l}\text { Quantity of smoking } \\
(\mathrm{n}=76)\end{array}$ & $\begin{array}{l}\text { Below half pack per day } \\
\text { Over half pack per day }\end{array}$ & & $\begin{array}{l}59(77.6) \\
17(22.4)\end{array}$ \\
\hline & $\begin{array}{l}\text { Smoking pack year } \\
(\mathrm{n}=76)\end{array}$ & $\begin{array}{l}\text { Below } 7 \text { pack-year } \\
\text { Over } 7 \text { pack-year }\end{array}$ & & $\begin{array}{l}62(81.6) \\
14(18.4)\end{array}$ \\
\hline
\end{tabular}

*Duplicated count; O20=Haemorrhage in early pregnancy; O44=Placenta previa; O45=Premature separation of placenta (abruptio placentae); O46=Antepartum haemorrhage, not elsewhere classified; O67=Labour and delivery complicated by intrapartum haemorrhage, not elsewhere classified; O72=Postpartum haemorrhage; O85=Puerperal sepsis; O753=Other complications of labour and delivery, not elsewhere classified; O10=Pre-existing hypertension complicating pregnancy, childbirth and the puerperium; O11=Pre-existing hypertensive disorder with superimposed proteinuria; $\mathrm{O} 12=$ Gestational (pregnancy-induced) oedema and proteinuria without hypertension; O13=Gestational (pregnancy-induced) hypertension without significant proteinuria; O14=Gestational (pregnancy-induced) hypertension with significant proteinuria; O15=Eclampsia; O16=Unspecified maternal hypertension; O64=Obstructed labour due to malposition and malpresentation of fetus; O65=Obstructed labour due to maternal pelvic abnormality; O66=Other obstructed labour; O00=Ectopic pregnancy;,O01=Hydatidiform mole; O02=Other abnormal products of conception; O03=Spontaneous abortion; O04=Medical abortion; O05=Other abortion; O06=Unspecified abortion; O07=Failed attempted abortion; O08=Complications following abortion and ectopic and molar pregnancy; P07=Disorders related to short gestation and low birth weight, not elsewhere classified; P22=Respiratory distress of newborn; P25=Interstitial emphysema and related conditions originating in the perinatal period; P26=Pulmonary haemorrhage originating in the perinatal period; $\mathrm{P} 27=$ Chronic respiratory disease originating in the perinatal period; $\mathrm{P} 28=\mathrm{Other}$ respiratory conditions originating in the perinatal period; P612=Anaemia of prematurity; P77=Necrotizing enterocolitis of fetus and newborn; P52=Intracranial nontraumatic haemorrhage of fetus and newborn; H351=Retinopathy of prematurity; P11=Other birth injuries to central nervous system; P21=Birth asphyxia; P91=Other disturbances of cerebral status of newborn. 
Table 2. Differences of the Number of Diseases by General Characteristics and Smoking Behaviors

$(N=382)$

\begin{tabular}{|c|c|c|c|c|}
\hline \multirow[t]{2}{*}{ Variables } & & \multirow[t]{2}{*}{ Categories } & \multicolumn{2}{|c|}{$\begin{array}{c}\text { Number of maternal conditions and conditions } \\
\text { arising during the perinatal period }\end{array}$} \\
\hline & & & $\mathrm{M} \pm \mathrm{SD}$ & $\mathrm{t}(p)$ \\
\hline \multirow{2}{*}{\multicolumn{2}{|c|}{ Age group }} & $15 \sim 34(n=181)$ & $2.14 \pm 0.41$ & $1.09(.044)$ \\
\hline & & $35 \sim 44(n=201)$ & $4.49 \pm 0.52$ & \\
\hline \multirow[t]{8}{*}{ Smoking behavior } & \multirow{2}{*}{$\begin{array}{l}\text { Smoking status } \\
(\mathrm{n}=382)\end{array}$} & Never smoke $(n=296)$ & $1.82 \pm 0.53$ & $1.53(.002)$ \\
\hline & & Experience (ex and current) $(n=86)$ & $4.85 \pm 0.44$ & \\
\hline & \multirow{2}{*}{$\begin{array}{l}\text { Duration of smoking } \\
(\mathrm{n}=86)\end{array}$} & Below 5 years $(n=60)$ & $2.10 \pm 0.38$ & $1.44(<.001)$ \\
\hline & & Over 5 years $(n=26)$ & $4.89 \pm 0.22$ & \\
\hline & \multirow{2}{*}{$\begin{array}{l}\text { Quantity of smoking } \\
(\mathrm{n}=76)\end{array}$} & Below half pack $(n=59)$ & $3.16 \pm 0.26$ & $2.86(.217)$ \\
\hline & & Over half pack $(n=17)$ & $3.58 \pm 0.31$ & \\
\hline & \multirow{2}{*}{$\begin{array}{l}\text { Smoking pack year } \\
(\mathrm{n}=76)\end{array}$} & Below 7 pack-year $(n=62)$ & $2.62 \pm 0.29$ & \multirow[t]{2}{*}{$1.91(.005)$} \\
\hline & & Over 7 pack-year $(n=14)$ & $3.33 \pm 0.18$ & \\
\hline
\end{tabular}

Table 3. Correlation between the Number of Diseases and Major Variables

\begin{tabular}{|c|c|c|c|c|c|c|c|c|}
\hline \multirow{2}{*}{ Variables } & 1 & 2 & 3 & 4 & 5 & 6 & 7 & 8 \\
\hline & $\mathrm{r}$ & $\mathrm{r}$ & $\mathrm{r}$ & $\mathrm{r}$ & $\mathrm{r}$ & $\mathrm{r}$ & $\mathrm{r}$ & $\mathrm{r}$ \\
\hline 1. Age & 1 & & & & & & & \\
\hline 2. Blood pressure & $.40^{* *}$ & 1 & & & & & & \\
\hline 3. BMI & -.07 & $.64^{* *}$ & 1 & & & & & \\
\hline 4. Smoking status & $.21^{* *}$ & $.55^{*}$ & -.19 & 1 & & & & \\
\hline 5. Duration of smoking & $.23^{* *}$ & .17 & -.22 & $.28^{* *}$ & 1 & & & \\
\hline 6. Quantity of smoking & .11 & $.31^{* *}$ & .32 & $.11^{*}$ & -.76 & 1 & & \\
\hline 7. Smoking pack year & $.14^{\star *}$ & $.18^{* *}$ & .20 & $.08^{*}$ & .19 & $.33^{* *}$ & 1 & \\
\hline 8. Number of diseases & $.59^{* *}$ & $.24^{* *}$ & $.43^{* *}$ & $.14^{*}$ & $.22 * *$ & .65 & $.11^{*}$ & 1 \\
\hline
\end{tabular}

${ }^{*} p<.005 ;{ }^{* *} p<.001 ;$ BMI=Body mass index.

Table 4. Factors Affecting the Number of Maternal Conditions and Conditions Arising during the Perinatal Period of Smoking Behaviors

$(N=382)$

\begin{tabular}{|c|c|c|c|c|c|c|c|}
\hline \multirow{2}{*}{ Variables } & & \multicolumn{3}{|c|}{ Model 1} & \multicolumn{3}{|c|}{ Model 2} \\
\hline & & B & $\beta$ & $\mathrm{t}(p)$ & B & $\beta$ & $\mathrm{t}(p)$ \\
\hline Age & & $.08^{* *}$ & $.13^{* *}$ & $0.66(<.001)$ & $-1.03^{\star *}$ & $-.77^{* *}$ & $1.01(<.001)$ \\
\hline BMI & & $.22^{* *}$ & $.53^{* *}$ & $1.71(.004)$ & 0.32 & .60 & $1.12(.145)$ \\
\hline Blood pressure & $\begin{array}{l}\text { Systolic } \\
\text { Diastolic }\end{array}$ & $\begin{array}{r}-.02 \\
.14\end{array}$ & $\begin{array}{r}-.11 \\
.20\end{array}$ & $\begin{array}{l}1.01(.149) \\
2.31(.221)\end{array}$ & $\begin{array}{l}1.17^{* *} \\
1.02\end{array}$ & $\begin{array}{l}.45^{* *} \\
.25\end{array}$ & $\begin{array}{l}2.36(.008) \\
2.91(.317)\end{array}$ \\
\hline Smoking habit & $\begin{array}{l}\text { Smoking status } \\
\text { Duration of smoking } \\
\text { Quantity of smoking } \\
\text { Smoking pack year }\end{array}$ & & & & $\begin{array}{l}1.78^{\star *} \\
1.10^{\star *} \\
1.35 \\
1.44\end{array}$ & $\begin{array}{l}.92^{* *} \\
.33^{* *} \\
.79 \\
.27\end{array}$ & $\begin{array}{l}1.92(.001) \\
0.08(.019) \\
2.42(.701) \\
1.21(.122)\end{array}$ \\
\hline Adjusted $\mathrm{R}^{2}$ & & \multicolumn{3}{|c|}{.278} & \multicolumn{3}{|c|}{.659} \\
\hline $\mathrm{F}(p)$ & & \multicolumn{3}{|c|}{$1.62(.054)$} & \multicolumn{3}{|c|}{$7.01(.002)$} \\
\hline
\end{tabular}

BMI=Body mass index. 
cantly higher than for younger women. In elderly pregnancies, it was reported that the incidence of negative pregnancy outcome is higher compared to pregnancies under 35 years of age [9]. Several studies have reported on the negative effects of maternal aging on fetal and maternal outcomes, such as increased occurrence of low birth weight infants, severe maternal defects, high fetal and neonatal defects and mortality [912]. In particular, the average age of marriage and reproductive aging has been increasing steadily since the 21st century due to economic factors such as employment status, housing, and child care costs, and social structural factors such as work-family compatibility and gender discrimination [13]. The average marriage age of Korean women increased from 26.5 years in 2000 to 30.2 years in 2017, while the reproductive aging of primiparous mothers increased from 27.7 years in 2000 to 31.4 years in 2017 [13].

In Korea, the rate of premature and low birth weight infants is increasing due to the age of women becoming pregnancy, the smoking rate during pregnancy, the increase of multiple births, and changes in the social environment [14]. Smoking is an important risk factor for premature and low birth weight infants. Because nicotine and cadmium in cigarettes contracts blood vessels and reduces intrauterine blood flow, they adversely affect fetal and placental development. Indeed, it is difficult to sustain a pregnancy if the fetus becomes hypoxic if blood vessels contract due to nicotine, placental blood flow becomes restricted due to the pathology of placental blood vessels, and the oxygen supply decreases due to elevation of the carboxyhemoglobin level [15-17].

In Korea, women tend to hide their smoking behavior due to social taboos against women smoking [2]. In this study, only $40.3 \%$ (382 of 947) of the subjects who experienced maternal conditions and conditions arising during the perinatal period responded to our smoking behavior survey, with only $19.9 \%$ (76 of 382) of the respondents answering that they had smoked. Women smoking is perceived very negatively in East Asian countries such as South Korea, Japan, and China which have been influenced by Confucianism [18]. Therefore, women tend to under-report their smoking behavior in surveys. These countries' self-reported surveys (SRs) tend to produce results that underestimate the number of women smokers, owing to the social desirability response bias. Therefore, it is necessary to compare the results of SRs with the urinary cotinine samples in order to obtain a more accurate smoking rate [18].

In the panel data, health behaviors were surveyed using a self reported questionnaire during a regular health examination. To ensure the accuracy of our data, a nicotine test using urine was performed in parallel with the survey. Asian women are more affected by social structural influences and envi- ronmental factors than men, such as having close friends or other people recommending tobacco use, are also affected, especially when smoking is perceived as normal by women [8]. In addition, since reasons for first smoking, reason for continuing to smoke, and the process of smoking cessation are different between women and men, a practical smoking cessation program is needed to reduce smoking rates, by taking factors that affect women's smoking into account [14].

According to the WHO, over the past 20 years, 100,000 babies have lost their lives due to sudden infant syndrome, premature infant complications, and being underweight due to their parents' smoking [15]. Although many scientific studies have explored the negative effects of smoking on the fetus, $20 \sim 50 \%$ of pregnant women are still exposed to smoking or secondhand smoke, and there are signs that young women are increasingly smoking during pregnancy $[16,17]$. In the United States, about $10 \%$ of pregnant women smoked during the last 3 months of pregnancy, and the rate of smoking cessation during pregnancy was only about $20 \%[16,17]$. Therefore, it is important that smoking education start before pregnancy [16, 17]. In Korea, a total of 1,090 self-reported surveys and 1,057 urine samples were analyzed, The percentage of smoking revealed by self-reporting was $0.55 \%$ and that revealed by urinary cotinine measurement $(>100 \mathrm{ng} / \mathrm{mL}$ ) was $3.03 \%[19]$, an almost 6 times discrepancy.

In the present study, we found differences between age groups in terms of maternal conditions and conditions arising during the perinatal period in the period of smoking. Especially, the amount and duration of smoking are proved to be significant factors causing pregnancy-related diseases. In our regression analysis, we added smoking behavior to find maternal conditions and conditions arising during the perinatal period significantly increase in the explanatory power of the model and that smoking status and smoking cessation affects the maternal conditions and conditions arising during the perinatal period; in particular, the systolic blood pressure of the subjects was significantly influenced by smoking behavior.

This study confirmed the association between maternal smoking during pregnancy and the risk of child birth-related diseases in mothers from all age groups. Smoking affects the growth of the fetus and the placenta compared to non-smokers, resulting in a low birth weight child [20]. However, in the previous Korean study, $25 \%$ of women smokers are reported to smoke during pregnancy, and $23 \sim 40 \%$ of smokers quit smoking during pregnancy, though $70 \%$ began again after giving birth [3]. Smokers are more likely to quit smoking if they have higher level of education, are provided with more support from their husbands and have more children; yet, the younger the age, the higher the percentage of smokers during 
pregnancy [21]. Particularly, quitting smoking was especially difficult for pregnant women in the younger age group. In Norman, in an in-depth interview of 52 pregnant women, participants were found to naturally quit smoking at the beginning of pregnancy, but most of them smoked again during pregnancy [22]. In a different study of 534 adolescent mothers, the researchers analyzed the effects of smoking on the weight of newborn infants and found $46.2 \%$ of them smoked during pregnancy, also showed that smoking behavior has more influence on pregnant and childbirth-related illnesses in younger-age mothers [23], suggesting that a smoking cessation program for younger mothers is necessary.

Therefore, if a pregnant woman visits a counseling center for smoking cessation, she should be advised to receive medical care for prenatal care and also be provided education on how smoking affects the mother and fetus [14]. The Framework Convention on Tobacco Control (FCTC) recommends that smoking cessation programs take into account the characteristics of the population. Thus, 115 of the WHO Tobacco Counterparties are reporting that they are carrying out this provision, with $71 \%$ providing services for pregnant women [24]. However, in Korea, only a few institutions provide such pregnant women education programs, and despite some research on smoking cessation or support programs for emotional workers, little attention has been given to the development of a smoking cessation policy that reflects the needs of women [25]. In addition, most studies have assessed the mortality and risks arising from smoking or have looked at correlations between smoking and various diseases [26,27], regardless of gender. Few have studies, the effects of smoking on maternal conditions and conditions arising during the perinatal period. Therefore, it is necessary to develop a smoking cessation education program for pregnant women in Korea, a program in which the characteristics and age of women are given special consideration.

The purpose of this study was to analyze the effects of smoking behavior of pregnant women on maternal conditions and conditions arising during the perinatal period, using National Health Insurance Corporation medical panel data from 2009 to 2014. Overall, the results of this study showed that the effects of smoking behavior on maternal conditions and conditions arising during the perinatal period were significant.

Nonetheless, there is a limitation in the panel data of the National Health Insurance Corporation since various variables are not included in the smoking behavior of women who are pregnant. Therefore, in a follow-up study, a cohort study for the same persons need to be performed in order to integrate various factors in analysis, including interaction effects.

\section{CONCLUSION}

The purpose of this study was to analyze the effects of smoking behavior of pregnant women on maternal conditions and conditions arising during the perinatal period, using National Health Insurance Corporation medical panel data from 2009 to 2014. The results of this study showed that there are the effects to be significant. Therefore, it is necessary to develop a smoking cessation education program for pregnant women in Korea, a program in which the characteristics and age of women are given special consideration.

\section{Conflict of interest}

No potential or any existing conflict of interest relevant to this article was reported.

\section{REFERENCES}

1. OECD. OECD health statistics 2018 [Internet]. France: OECD; 2018 [cited 2018 June 20]. Available from:

http://www.oecd.org/els/health-systems/health-data.htm.

2. Jung-Choi KH, Khang YH, Cho HJ. Hidden female smokers in Asia: A comparison of self-reported with cotinine-verified smoking prevalence rates in representative national data from an Asian population. Tobacco Control. 2012;21(6):536-542.

https://doi.org/10.1136/tobaccocontrol-2011-050012

3. Statistics Korea. 2016 smoking rate [Internet]. Seoul: Statistics Korea; 2016 [cited 2018 May 10]. Available from:

http://kosis.kr/statHtml/statHtml.do?orgId=101\&tblId=DT_2K AAC04_OECD.

4. Ministry of Health and Welfare of Korea, Korea Centers for Disease Control and Prevention. 2016 Korea health statistics [Internet]. Seoul: Ministry of Health and Welfare of Korea; 2016 [cited 2018 May 8]. Available from:

http://www.index.go.kr/potal/enaraIdx/idxField/userPageCh. do?chkURL=/potal/stts/idxMain/selectPoSttsIdxMain.do\%3Fcl as_div\%3DC\%26idx_cd\%3D2771\%26bbs\%3DINDX_001\&idx_cd $=2771 \&$ Title $=\%$ EC $\% 9 \mathrm{D} \% 8 \mathrm{C} \% \mathrm{EC} \% \mathrm{A3} \% \mathrm{BC}+\% \mathrm{ED} \% 98 \% 84 \% \mathrm{ED} \% 9$ 9\%A9\&playurlstr=http://www.index.go.kr/potal/main/EachDt 1PageDetail.do\%3Fidx_cd\%3D1446.

5. Sung CJ, Bae YJ. The study on nutritional status, bone mineral density and plasma mineral concentrations of smoking male adults. Korean Journal of Community Nutrition. 2005;10(1):91-100.

6. Hong KE. An analysis of the factors influencing smoking behavior of Korean female college students. Journal of Korean Society for Health Education and Promotion. 2002;19(3):13-34.

7. Hwang SJ, Oh SW, Kim SN, Hwang HS, Cho BL, Huh BY. Smoking patterns and factors associated with smoking in Korean adult women. Journal of Korean Academy of Family Medicine. 2000;21(3): 
344-356.

8. Bouyer J, Coste J, Shojaei T, Pouly JL, Fernandez H, Gerbaud L, et al. Risk factors for ectopic pregnancy: A comprehensive analysis based on a large case-control, population-based study in France. American Journal of Epidemiology. 2003;157(3):185-194.

9. Manaf RA, Shamsuddin K. Smoking among young urban Malaysian women and its risk factors. Asia Pacific Journal of Public Health. 2008;20(3):204-213. https://doi.org/10.1177/1010539508316973

10. Lean SC, Derricott H, Jones RL, Heazell AEP. Advanced maternal age and adverse pregnancy outcomes: A systematic review and meta-analysis. PLoS One. 2017;12(10):e0186287.

https://doi.org/10.1371/journal.pone.0186287

11. Harrison BJ, Hilton TN, Rivière RN, Ferraro ZM, Deonandan R, Walker MC. Advanced maternal age: Ethical and medical considerations for assisted reproductive technology. International Journal of Women's Health. 2017;9:561-570.

https://doi.org/10.2147/IJWH.S139578

12. Ogawa K, Urayama KY, Tanigaki S, Sago H, Sato S, Saito S, et al. Association between very advanced maternal age and adverse pregnancy outcomes: A cross sectional Japanese study. BMC Pregnancy and Childbirth. 2017;17(1):349. https://doi.org/10.1186/s12884-017-1540-0

13. Statistics Korea. Reproductive aging [Internet]. Seoul: Statistics Korea; 2017 [cited 2018 July 5]. Available from: http://kosis.kr/statHtml/statHtml.do?orgId=101\&tblId=DT_1B80 00F\&vw_cd=MT_ZTITLE\&list_id=A2_6\&seqNo=\&lang_mode $=\mathrm{ko}$ \&language=kor\&obj_var_id=\&itm_id=\&conn_path=MT_ZTITLE.

14. Seo MK. Smoking status and issues of women in the world. Smoking Policy Forum Tobacco-Free. 2015;5:8-18.

15. Ko TJ, Tsai LY, Chu LC, Yeh SJ, Leung C, Chen CY, et al. Parental smoking during pregnancy and its association with low birth weight, small for gestational age, and preterm birth offspring: A birth cohort study. Pediatrics Neonatology. 2014;55(1):20-27. https:// doi.org/10.1016/j.pedneo.2013.05.005

16. Šumichrastová P, Škorňová I, Kúdela E, Siváková J, Hrtánková M, Švecová I, et al. Negative effects of maternal smoking on pregnancy and the fetus in relation to elevated levels of erythropoietin in umbilical cord plasma. Open Journal of Preventive Medicine. 2014;4(5):307-316. https://doi.org/10.4236/ojpm.2014.45038

17. Jauniaux E, Suri S, Muttukrishna S. Evaluation of the impact of maternal smoking on ultrasound and endocrinological markers of first trimester placentation. Early Human Development. 2013;89
(9):777-780. https://doi.org/10.1016/j.earlhumdev.2013.06.005

18. Park MB, Kim CB, Nam EW, Hong KS. Does South Korea have hidden female smokers: Discrepancies in smoking rates between selfreports and urinary cotinine level. BMC Women's Health. 2014;14: 156. https:// doi.org/10.1186/s12905-014-0156-z

19. Jhun HJ, Seo HG, Lee DH, Sung MW, Kang YD, Syn HC, et al. Self-reported smoking and urinary cotinine levels among pregnant women in Korea and factors associated with smoking during pregnancy. Journal of Korean Medical Science. 2010;25(5):752-757. https://doi.org/10.3346/jkms.2010.25.5.752

20. Anblagan D, Jones NW, Costigan C, Parker AJJ, Allcock K, Aleong $\mathrm{R}$, et al. Maternal smoking during pregnancy and fetal organ growth: A magnetic resonance imaging study. PLoS One. 2013;8(7):e67223. https://doi.org/10.1371/journal.pone.0067223

21. Kharkova OA, Krettek A, Grjibovski AM, Nieboer E, Odland JØ. Prevalence of smoking before and during pregnancy and changes in this habit during pregnancy in Northwest Russia: A Murmansk county birth registry study. Reproductive Health. 2016;13:18. https://doi.org/10.1186/s12978-016-0144-x

22. Constantine NA, Slater JK, Carroll JA, Antin TMJ. Smoking cessation, maintenance, and relapse experiences among pregnant and postpartum adolescents: A qualitative analysis. Journal of Adolescent Health. 2014;55(2):216-221.

https://doi.org/10.1016/j.jadohealth.2013.12.027

23. Delpisheh A, Attia E, Drammond S, Brabin BJ. Adolescent smoking in pregnancy and birth outcomes. European Journal of Public Health. 2006;16(2):168-172. https://doi.org/10.1093/eurpub/cki219

24. Lee YJ. Practical understanding of smoking cessation counseling for female smokers. Smoking Policy Forum Tobacco-Free. 2015;5: 19-23.

25. Oh YM. Status and policy direction of female smoking. Smoking Policy Forum Tobacco-Free. 2015;5:2-7.

26. Park S, Jee SH, Shin HR, Park EH, Shin A, Jung KW, et al. Attributable fraction of tobacco smoking on cancer using populationbased nationwide cancer incidence and mortality data in Korea. BMC Cancer. 2014;14:406. https://doi.org/10.1186/1471-2407-14-406

27. Kim JA, Chun EJ, Lee MS, Kim KJ, Choi SI. Relationship between amount of cigarette smoking and coronary atherosclerosis on coronary CTA in asymptomatic individuals. The International Journal of Cardiovascular Imaging. 2013;29(1):21-28.

https://doi.org/10.1007/s10554-013-0224-8 